\section{Educating a Child with Down Syndrome in an Inclusive Kindergarten Classroom}

\section{Abstract}

This case study describes the journey of a kindergartner with Down Syndrome in an inclusive classroom. Characteristics of the participant are discussed in comparison to characteristics of children with Down Syndrome and the impact of those characteristics for the child's overall development. Various strategies that were effectively used to facilitate the child's participation, transitioning, academics, and social skills are addressed. The child's improvements in various areas of development as a result of inclusion in the kindergarten classroom are discussed. Finally, investigating the efficacy of inclusion for children with moderate to severe intellectual disabilities is recommended for further research.

Keywords: Down syndrome; Child; Inclusion; Kindergarten

\section{Lema Kabashi ${ }^{1 *}$ and Louise Kaczmarek ${ }^{2}$}

1 Department of Educational Studies, 300B Morris Hall, University of Wisconsin-La Crosse, United States

2 Department of Instruction \& Learning, Posvar Hall 5160, School of Education, University of Pittsburgh, Pittsburgh, PA 15260, United States

*Corresponding author: Lema Kabashi

戸Ikabashi@uwlax.edu

Department of Educational Studies, 300B Morris Hall, University of Wisconsin-La Crosse, United States.

Citation: Kabashi L, Kaczmarek L (2019) Educating a Child with Down Syndrome in an Inclusive Kindergarten Classroom. J Child Dev Disord. Vol.5 No.2:4

\section{Introduction}

Over the last decade, more children with disabilities are receiving more of their education in regular classroom settings. According to the most recent Annual Report to Congress [1], 81.4\% of children with disabilities, ages 6-21 years of age, spent at least $40 \%$ of their school day in the regular education classroom with $63.1 \%$ of those spending at least $80 \%$ time there. This contrasts with the report of ten years earlier in which only $77.4 \%$ were reported in regular classrooms a minimum of $40 \%$ with $53.7 \%$ spending at least $80 \%$ [2]. As more students with disabilities spend more time in regular education classrooms, providing appropriate special education and other related services to meet their needs is paramount.

Federal legislation, including the Individuals with Disabilities Education Improvement Act (IDEIA; (Ref, 2004), the Americans with Disabilities Amendments Act (ADAA; ref, 2008, the Every Student Succeeds Act (ESSA; ref, 2015) [3], has mandated equal access to public education for children with disabilities. The ESSA, in particular, has sought to maintain children with disabilities in accountability systems, to encourage the use of evidence-based practices to improve inclusive outcomes, and to support students with more severe cognitive impairments to access the general curriculum [4]. The identification evidence-based practices and the development of inclusive policies and programs has supported the legislative goals focused on improving the successful inclusion of children with disabilities in regular classrooms [5]. Beyond this focus on learning, there is also significant value in the interactions and relationships that are facilitated among children with and without disabilities in successful inclusive classrooms [6].

As more children with disabilities have been included in recent years, the number of children with moderate and severe disabilities being served in regular classrooms has also increased [7]. However, including children with more severe disabilities continues to be challenging $[7,8]$. Successful inclusion, for these students especially, is related to consistent and intentional collaboration of regular and special education teachers in which the regular education teacher is responsible for the implementation of the general curriculum and the special educator is the expert in designing child-specific evidence-based interventions, adaptations, and accommodations [8,9].

For young children, a crucial variable for the success of inclusion is remaining full time in the same classrooms with their typically developing peers rather than sharing activities for a part of the day. Active engagement, which represents the amount of time the child spends interacting with the environment in a developmentally and contextually appropriate manner [10], is a highlight of inclusion [11]. Active engagement is the foundation 
for effective learning in children with disabilities [10]. Given the expectations for children with disabilities to learn from typically developing children, develop social interactions, and form relationships with them [12], children with disabilities need to be spending a significant portion of their day around their typically developing peers.

Historically, children with Down Syndrome (DS) have been educated in separate special education classrooms and schools. Today, however, most children with mild to moderate disabilities, such as those manifested by children with DS [13], are likely placed in regular classrooms for most of their school day [7]. Research has shown that children with DS benefit both academically and socially by going to school with their typically-developing peers [14]. Education in inclusive classrooms has proven to be beneficial for children with DS in areas such as communication, academics, social functioning and participation, and independence to carry out routine activities and everyday tasks [15].

Factors that teachers have reported as important to the successful inclusion of children with moderate disabilities include working collaboratively with the multidisciplinary team, creating learning opportunities that are individualized and differentiated, and developing learning materials [8]. In addition, the use of visual supports and manipulatives, collecting, analyzing, and using data for planning and decision-making, providing choices, teaching social skills, facilitating teacher planning time, and promoting frequent home-school communication are recommended [7] Students with and without disabilities who were involved in successful inclusion reported a positive school culture of belonging, a unique school community that emphasized similarities rather than differences, and the importance of individual supports for the success of all students [6]. The perspectives of these students reflect the goals of inclusion to promote a child's participation in all school and classroom routines and activities through the use of accommodations, facilitate learning through the use of evidence-based practices; and foster interaction and friendships with peers to achieve a sense of belonging [16].

In light of these overarching goals, we have chosen to organize this case study around these goals. The purpose is to demonstrate how the participation level in daily activities, social functioning, and academic achievement were effectively increased in a child with DS who was included in a regular kindergarten classroom. This account will highlight the implications of the child's developmental level in the inclusive setting as well as the types of teaching strategies used to facilitate the child's participation, social functioning, and academic achievements.

\section{Down Syndrome: Characteristics and Implications}

Down syndrome is the leading genetic cause of intellectual disability, currently affecting approximately one in every 737 newborns in the United States [17]. The majority of children with DS have Trisomy 21, which means that there are three $21^{\text {st }}$ chromosomes present rather than the standard two [18]. However, there are also two other causes of DS -- one being called
Translocation, which occurs as a result of part of chromosome 21 being attached to another chromosome, and the other one called Mosaicism, known to be the rarest cause of DS, and occurs due to a nondisjunction of chromosome 21 that places an additional copy of the chromosome in some cells [19].

Given that approximately $95 \%$ of cases of DS are caused by a third chromosome 21 [20], it is important to know that this extra genetic material is responsible for substantial abnormalities in the structural design and brain functioning at birth and continues to compromise brain development all the way through childhood years to adulthood [18]. Facial and musculoskeletal features, growth retardation, low height, short extremities, congenital heart defects, anomalies of the gastrointestinal tract, childhood leukemia, visual impairment, hearing impairment, hypotonia and tendency towards obesity are some of the physical characteristics and/or risks that characterize this population $[19,21]$. Tony (pseudonym), the child that is going to be discussed in this paper, was a 5-years boy with diagnoses of DS. Tony's facial and musculoskeletal features such as a small chin, slanted eye, a flat nasal bridge, a small moth and a large tongue [22] were attributed to DS. Hypotonia, which strongly impacted his physical strength compared to his peers, was present as well. As a result of hypotonia and loose joints he often experienced coordination difficulties. He exhibited the ability to walk up and down the stairs placing both feet on the step and holding onto railings, but had difficulty using alternating feet. His fine motor skills impacted his ability to effectively manipulate writing utensils. Although Tony experienced respiratory infections, hearing problems, and dental problems, they did not seriously impact his overall abilities to participate and perform throughout daily school activities.

In addition to genetic and physical features, children with DS display linguistic deficits with a discrepancy between expressive and receptive language capabilities, consisting of a greater discrepancy in vocabulary compared to mental age as well as impairments in grammar development. This usually means that in many children language does not develop beyond the early phases of development of morphology and syntax, which is a serious barrier to learning $[23,24]$. In this respect, Tony had a smaller vocabulary then his peers, thus less general knowledge. He also experienced problems with grammar, which resulted in connecting words left out. His receptive language was significantly greater than his expressive language. Even though Tony made attempts to produce more sophisticated sentences, he had difficulty in producing extended sentences due to articulation problems. He demonstrated the ability to repeat words in the order presented but demonstrated difficulty in repeating what happened in a story previously read by another. Such language difficulties often times are related to hypotonia, affecting greatly speech production, memory difficulties, and auditory perception [25].

Cognitive abilities in children with DS are greatly compromised, varying widely from severe impairment to near normal intelligence [19]. They typically display an IQ between 30 and 70, with a mean being near 50, and with impairments greater in some domains of cognition than in others [21]. Memory is another cognitive area 
in which individuals with DS present difficulties, particularly in short-term memory, working memory, and in explicit long-term memory [26]. Tony's impairments in the cognitive domain placed him on the higher end of the above mentioned IQ equation. In general, he demonstrated the ability to identify some letters of the alphabet as well as letters involved in his first and last name. He demonstrated the ability to identify and name fundamental colors. He also could count correctly, with some assistance, up to 5 , and identify a few geometrical shapes. Tony was capable of imitating a pattern with blocks of two different colors, but he experienced difficulty in making patterns of three and more colors. He matched like objects based on appearance and/or function when prompted, as well as identified a familiar object when only part of it was shown. Although Tony enjoyed singing and dancing, he had difficulty imitating complex movement patterns or follow multi-step instructions.

Features that characterize the area of social development of children with DS include an affectionate nature, social withdrawal, and significant emotional and conduct problems with noncompliance, aggression, and hyperactivity [27]. In regard to social and emotional skills, Tony was considered a very happy child with a great sense of humor. He interacted with peers mainly by hugging them and playing rough and tumble games. From the outset, most of Tony's classmates were quite affectionate toward him. They would attempt to hold hands, hug him, or sit next to him during activities such as lunch, line-up, and circle time. He usually struggled with accepting and returning the affection to his peers as well as initiating interaction or entering and maintaining a conversation with peers/adults. He preferred solitary play or parallel play over peer or group play, usually without disrupting work or play of others. Tony cooperated when asked to be quiet after an active period; on rare occasions he displayed behaviors that were not appropriate to the situation or place. Verbalizing his feelings appropriately was quite difficult for him. In situations where he became upset or frustrated, he would not be able to label or explain his feelings even if prompted by adults or peers. According to Alton [25] it is common for children with DS to display such behaviors due to speech and language problems, memory, coordination, concentration, and learning differences.

\section{Inclusive Setting}

The child with DS was the only child with disabilities being educated in this inclusive kindergarten classroom. There were two co-teachers who cotaught in this classroom, in addition to other teachers (e.g., Spanish, Art, etc.) or other staff who came in the classroom to provide related services (e.g., speech and language therapist, occupational therapist, etc.) to the child with DS. In addition, there was a doctoral student in Early Intervention who supported the child with DS in daily activities throughout the school year.

\section{Facilitation Strategies}

Studies that have investigated teacher views on inclusive education have indicated the majority of teachers do not consider regular education classrooms as the best option for children with disabilities. In fact, their attitudes towards inclusion became less positive as the teaching experience increased [28]. Teacher concerns included the quantity of individualized time that children with disabilities need, putting other students at a disadvantage; apprehension of the quality of work created by children with disabilities; deficiencies in support services and in their expertise and training in the skills necessary to sustain inclusive education [29]. The teachers in Tony's classroom expressed similar concerns. Consequently, a special education consultant was engaged to assist the teachers in the development of strategies that would lead to successful inclusion. These strategies are described below.

\section{Strategies that facilitate participation and transitioning}

In order for children to be able to participate successfully in their dailyschool activities, skills such as paying attention to the teachers, following their directions, being able to communicate their needs, and have adaptive skills that promote their independence, are considered critical. Task completion, participating in small and large group activities, and interaction engagement with peers are considered essential as well [30]. Paying attention to the teacher and following the teacher's directions represented a difficult task for Tony. He usually did not experience difficulty engaging in large group activities when provided assistance, or if the activity itself was one that he preferred. Familiar activities and those that included fairly few steps did not represent an issue for him either. However, engaging in activities that contained new content, were long, or included such complexities as multiple steps or many children were quite difficult for him. Activities that required the use of language or writing were challenging as well.

Although transitioning in general was very challenging for Tony, transitioning from a preferred activity to a non-preferred activity was even more difficult. When it was time to start another activity, Tony often dropped to the floor, ignored teachers' requests, ran away, grabbed a favorite toy and started playing with it, or went to his favorite library location without the teachers' permission. Teachers' and peers' verbal and gestural prompting did not usually facilitate a timely transition. To address these issues, two primary strategies were implemented to assist Tony in learning the expectations of his new classroom and facilitating his transition between activities.

The School-to-Home reward program: A school-to-home reward program was initiated by Tony's parents and implemented by school professionals. This reward program required joint efforts and close collaboration from both school professionals and parents. Tony's parents developed two sets of cards, three cards each set, one for the morning and the one for the afternoon activities. The cards were made from a green card board, $5 \mathrm{x}$ 5 inch size. Each set of cards consisted of one smiley face, one neutral face, and one sad face. Within each card a word, in capital letters, describing the part of the day (i.e., "MORNING" or "AFTERNOON") was written. In addition, Tony's preferred food item (i.e., ice cream) and a preferred activity (i.e., watching a movie (TV) were clearly hand-drawn in each of the cards. 
Following the morning and the afternoon activities, a teacher observed and reviewed Tony's performance with him. Subsequently, based on his performance, Tony received a smiley, neutral, or a sad face for the morning and the afternoon activities. Tony favored ice cream and watching movies over all other things and they continued to be the most powerful reinforcers during the whole school year. If he was "awarded" with two smiley faces, one for attendance and participation in the morning school activities and the other for the attendance and participation in the afternoon school activities, at home he was rewarded with preferred items/activities, ice cream and a movie. If he received only one smiley face, then he was rewarded with only ice cream or only a movie (parents decision). In cases when he did not receive any smiley faces, he received neither. The school-to-home reward program, implemented in a strong collaboration between the family and the school, resulted in increasing smooth transitions throughout daily activities, improving his attendance and participation in daily activities, and near elimination of disruptive behaviors displayed previously in transition situations.

Picture activity schedule: Another influential factor in Tony's adaptation to the new setting was the institution of a picture activity schedule. After instituting a picture activity schedule, Tony learned to follow the daily schedule, first with assistance from a teacher and then independently. The picture schedule not only assisted Tony in smoothly transitioning between activities, but also reinforced his actual participation throughout daily activities. A study by Dooley et al. [31] showed that the use of picture activity schedules facilitated the smooth transitions of children with disabilities, enabling them to keep track of daily events and improving their understanding of timeframes and environmental sequences. To support the use of visual communication messages with children with disabilities, Quill [32] stressed the stability of visual messages in allowing the element of time necessary for the children to disengage, shift, and reengage attention. Given that Tony's performance increased greatly when the tasks were presented visually rather than auditorily, the use of the picture activity schedule proved to be a beneficial strategy.

The picture activity schedule consisted of colored photographs of school settings (i.e., gym, cafeteria, etc.) and/or different school materials (e.g., words of the daily schedule for opening, a xylophone, the instrument he adored, for music) combined with printed words representing each activity in the daily schedule. Before each activity, Tony would walk to the picture schedule located on the front bulletin board. A teacher assisted him in checking the schedule thus enabling him to realize what activity was coming up next and helping him to understand the expectations of the activity. Later, when he learned the routine and the expectations, he became comfortable checking the schedule independently and usually returned to his seat without teacher or peer prompting. After each activity, Tony flipped the activity card over and then explained to the teacher, at first with teacher prompting and later on independently, what that particular activity had been about and how he had participated in it. If his behavior met the expectations for that activity, the teacher praised him verbally and rewarded him with a sticker of his choice, which he would put on the back of the picture. Whenever his behavior did not meet the expectations for that particular activity, the teacher would explain to him the reasons why he was not receiving a sticker.

\section{Strategies that facilitate academics}

Given that the cognitive development of children with DS is greatly compromised, it is crucial to acknowledge that motivation to learn may be compromised due to few positive learning experiences [33]. It is very common for children with DS to develop avoidance strategies to decrease task demands and requests to perform. As a consequence, they avoid the cognitive demands; refuse to engage for longer period of time, often using subtle social maneuvers to sidetrack attention to activities that are less demanding [25]. To describe their learning style, Wishart [33] emphasized their (a) use of avoidance strategies when required to learn new skills, (b) unwillingness to take initiative in gaining knowledge, and (c) over-dependence on their social skills in learning contexts. The following strategies were implemented in order to help Tony avoid these typical difficulties and excel in academic skills.

Choice making: It was common for Tony to display challenging behaviors whenever presented with task demands. One of the strategies that proved to be beneficial was to offer Tony choices as a strategy for preventing challenging behaviors. There is a growing acknowledgement that children with disabilities have equal rights with their typically developing peers when it comes to making choices or expressing their preferences and having those preferences determine their decisions [34]. Choice making is the act of selecting an activity from among several familiar options at a particular moment in time [35]. Peterson, et al. [36] recommended using choice making in a situation when the child displays a behavior to either obtain something (e.g., attention, item) or avoid something (e.g., task, demand). Kern et al. [37] suggested using choice making for academic purposes as well. It has been noted that academic accuracy is greater when the child controls both task and reinforcer conditions rather than when the teacher controls those conditions.

Accordingly, given the opportunity to make his own choices about certain situations encouraged Tony to get engaged in a variety of class activities. This strategy was very effective in activities such as painting, drawing, and writing. For instance, Tony was provided with a choice between two different colors to paint, markers vs. crayons, slate board vs. handwriting book. Allowing him to make choices provided him with the necessary "power" to control the situation. The spoken, visual, and tangible choices he was given increased his participation in activities throughout the day and also resulted in greater compliance with the teacher's requests. As a result of the choice-making strategy, Tony started sharing his opinion about his peers during activities such as "Birthday parties" where he would draw or write his birthday wishes for that particular peer choosing his preferred colors or materials. He also developed greater interest to engage himself in the same activities as typically developing children. However, 
it is important to mention that choices needed to be encouraging and meaningful to him in order to increase his motivation and self-esteem to participate alongside his peers.

Breaking tasks down into small, incremental steps: This strategy has been proven to work well for children with disabilities because breaking the material into small, manageable parts allows them to succeed, thus improving their self-esteem and their willingness to undertake more complex tasks [38]. It was important for Tony that tasks be broken into small steps to ensure that he finished them successfully. For example, in "Language Arts" writing the letter $\mathrm{M}$ was broken into small incremental steps. Although the steps were incremental for all the children, Tony's tasks were not only broken into smaller manageable steps but each step was also paired with a visual. First, he would use Benbow scissors to cut on the lines of the letter " $M$ ", adapted in size for his cutting skills. Second, he glued the letter " $M$ " on a piece of colored construction paper. Third, he cut on the lines of a rectangle that included a short sentence about the letter " $M$ ". Fourth, he glued the short sentence on the same colored construction paper, below the letter " $\mathrm{M}$ ". Fifth, he traced over the missing letter "M's" in the short sentence already displayed on a construction paper. Sixth, he used 5 marshmallows to decorate the letter " $M$ ". Finally, he had to write his first name on the back of his paper. At first, he needed the teacher's assistance in following the steps, but when he reached the consistency of the routine, he was able to finish the activity independently.

Since children with DS have difficulty with abstract concepts, providing hands-on materials enabled Tony to follow the steps and perform a meaningful task. Wolpert [39] supported the idea that hands-on and real materials are among the materials that work best for children with DS. In regard to real materials, Tony demonstrated incredible progress in his drawing when he was provided the opportunity to draw costumes in an art exhibition. He showed his first recognizable drawings as a result of being exposed to real materials.

Scaffolding: Making sure that a child does not avoid the task or displays a certain behavior to gain what he wants requires teachers task prompting, redirection to the task, and implementation of guided compliance [36]. In order to support Tony's learning, teachers used scaffolding to enable him to master a task that he initially was unable to achieve independently. Scaffolding means that during class interactions, teachers support students by providing clues, demonstrations, encouragement, questions and so forth, which are concordant with the children's capacities [40]. Although Tony usually responded to all the teachers in the same way, at times he would work and/or respond better to a certain teacher. In such circumstances, teachers would change roles in order to support him in a particular activity. Teachers used speech scaffolding, joint speech and gesture, and gesture scaffolding. Speech scaffolding consisted of giving cues, providing instructions, asking questions, prompting, reinforcing, and giving choices. For example, during a "Mystery Name" activity the teacher wrote three sentences regarding a child, whose name was picked. Then, after Tony would choose which sentence to write, the teacher dictated the letters of words so Tony would write the sentence that included his opinion and preferences regarding a peer. Speech and gesture scaffolding was implemented when directing his attention to a task using gestures. For example, if while writing a particular letter in a slate board he would get distracted and start playing with the sponge or the chalk, then the teacher would direct his attention to writing the letter as planned by pointing to the board and prompting him verbally to finish the task. Gesture scaffolding consisted mainly of modeling and demonstrating how to perform a task, especially in activities such as cutting, drawing, writing, painting and so forth. For example, while painting, the teacher would demonstrate how to use a clean brush when using different paint colors and then Tony would imitate the teacher and practice the skill.

Handwriting without tears: The Handwriting Without Tears is a program that includes intuitive workbooks, engaging hands-on materials, and lively music that inspires active learning [41]. Eight key components that characterize this program are:

a) memory-quick and automatic recall of letters and numbers,

b) orientation - facing letters/numbers in the correct direction,

c) placement - putting letters/numbers on the baseline,

d) size - how big/small a child chooses to write,

e) start - where each letter/number begins,

f) sequence - order and stroke direction of the letter/number parts,

g) control - neatness and proportion of letters/numbers,

h) spacing - amount of space between letters in words, and between words in sentences [41].

This program was very helpful with writing skills for Tony, especially the Slate Board. He liked writing some particular letters, such as F, E, I, H, and P on a slate board. Writing a letter in a slate board involved three steps. At first Tony needed prompting to follow the steps, which included at first writing the letter using a wet sponge, then tracing over the letter with white chalk, and finally erasing the letter using a wet sponge on the lines of the letter that was already written. After few months, Tony no longer needed prompting to follow the steps; it became the strategy he enjoyed most when writing upper case letters. Writing in different materials such as peanut butter, salt, sand, shaving cream, etc. increased his interest in writing as well. Nowadays, handwriting without tears has also created an app for iPad, Wet-Dry-Try, that simulates slate chalkboard and blackboard with double lines and makes that makes handwriting practice interesting and fun.

\section{Strategies that facilitate social skills}

Given that many children with DS are often described as "stubborn" and "obstinate" with attention problems, social withdrawal, noncompliance, and high rates of self-talk, it is understandable that inclusion can be challenging for families, peers, and professionals [42]. Tony's social withdrawal, solitary play, difficulty joining other children in an activity, and following 
steps and rules when engaging in group work presented quite a challenge for everyone. In order to facilitate Tony's social interactions and relationships with peers and adults, strategies such as social stories, video recordings/video feedback, pictures, and computer games/educational software were implemented. Such strategies assisted Tony in building better relationships with some of his peers, which improved even more later over the course of the school year; Tony not only started responding to peers'/adults' questions, but also complimented them, sat next to them, and played with them.

Social stories: Social stories are short individualized stories designed to teach a particular skill, behavior, or concept to a child. Given that social stories are written in the first person, they make it easier for the child to identify with the situation described in them [43]. A social story was designed to facilitate Tony's play skills with his peers. The focus of the social story was to increase play initiations with peers as well as join small and large group play activities. The teacher read the social story to him every day prior to outdoor activities. Tony's interest on social stories was not that high. As a result, Tony's responses toward peer initiations and joining them in preferred activities, with adults' assistance, increased, his play initiations with peers and adults did not improve.

Video self-modeling with video feedback: Video-based instruction (VBI) is an evidence-based practice that involves a child watching video footage of positive examples of adults, siblings, or peers engaging in the behavior that is being taught [44]. Video self-modeling, on the other hand, is a VBI strategy that consists of children watching themselves performing the targeted behavior(s) [45]. In general, Tony showed high interest in watching videos and pictures of others, but by the middle of the school year, he was extremely interested in watching himself in videos. In order to increase Tony's social interactions with peers, the teacher took advantage of his interest and made video recordings, targeting Tony's social interactions and play with peers. Given that he was interested in watching himself in the video, the teacher showed him videos where he displayed positive behavior and then gave him feedback on his positive behavior versus negative behavior, emphasizing the expectation for a certain situation presented in a video. As a result, Tony's motivation to participate in play activities with peers increased greatly. It was noted that, with teacher prompting, Tony's initiations with his favorite peers increased considerably.

Photographs: The use of photographs plays a key role in helping children with disabilities visualize appropriate social skills especially for those children who display visual strengths [46]. An advantage of implementing such a strategy with Tony was that he really liked having his picture taken and then enjoyed looking at them afterwards. Consequently, photos were used as reinforcers and motivators to increase social interactions with his peers. Pictures were taken with a digital camera in different daily activities such as opening, handwriting, free play, gym, field trips, and so forth. When a targeted behavior or situation was displayed or executed the teacher took pictures of them and then reviewed them with Tony. When appropriate skills such as engaging in reciprocal interaction/play with a peer, accurate drawing, or writing correct letters/words were documented in a picture the teacher provided positive feedback praising his behavior/achievement.

Computer games: The use of computers as a writing aid, learning tool, work station, and communication device with its multiple modes of output and well-defined rules and repeated practice has proven to be highly motivating for children with disabilities [47]. Introducing Tony to different computer games and educational software such as book reading, drawing, or entertaining spy games increased his ability to use the computer appropriately as well as increased his social skills with adults and peers. Specifically, the use of interactive computer software, which consisted of picture riddles, fun puzzles, and multi-leveled games, effectively increased Tony's social interaction when paired with typically developing peers. While exploring different special effects of the computer game, their communication increased, they both worked toward class expectations together, and used vocal, verbal, gestural, and facial expressions to ask questions and respond to the peer. The flexibility of computer technology provided Tony with the sense of independence and the special sound effects increased his interest to get engaged in the activity.

\section{Discussion}

This case study supports previous findings that children with DS benefit greatly from placement in inclusive settings [48]. By the end of the school year, both professionals and parents reported improvements in Tony's participation in everyday activities, social interactions with peers and adults, transitioning throughout daily activities, and academic achievements [49].

Tony experienced significant improvements in both gross and fine motor skills. His wide gait, even though still present in his walking, did not affect his active participation in different activities during recess and physical education. He learned to walk down the stairs independently, using alternating feet, often times without any support. He used alternating feet to walk up the stairs, although he still required railings or adults/peers support. He developed a special interest for physical activities, shown by his readiness to participate in the same activities as his peers without any modifications or accommodations in the activity or its materials. Improvements in fine motor skills were noticeable. Wrist and finger-strengthening activities immensely increased his ability to use writing manipulatives effectively. $\mathrm{He}$ was able to write his name accurately and neatly, print readable three-word sentences with adult assistance, and use a variety of colors in his drawings.

Tony's receptive and expressive language increased significantly. His vocabulary was considerably larger, his sentence structures, more complex, and his speech, more intelligible. As a result, his understanding of the curriculum increased as well. Active participation was noticed on activities that involved multistep instructions, which meant that he developed a better understanding of the types of instructions used in various 
academic areas, such as handwriting, language arts, art, and physical education.

Most obvious improvements were seen in the cognitive area. Given his strong visual ability, Tony started learning to read using the picture activity schedule. Then, still utilizing a whole-word approach, he moved to reading the same daily activity schedule that his peers read every morning. He could identify almost all alphabet letters. He learned to independently count up to 12 and with adults/peers assistance up to 20 . He also learned a few words in Spanish as well as to count correctly up to 10 . His art work improved from one color scribbles to meaningful and colorful drawings, which he often proudly showed to peers and adults. He wrote his first name independently and with some assistance his last name as well. He demonstrated the ability to write short sentences when the teacher dictated the letters of the words that formed a particular sentence.

Although Tony's social interactions with peers improved, this was the area that still needed more improvement. Tony responded frequently and appropriately to peer or adult initiations, but his initiations, which did increase from the beginning of the year, were still displayed at a low rate. He remained quite affectionate with his peers and developed close relationships with two of them. He also developed closer relationships with his teachers. He became much more responsive toward all teacher requests even though he tended to be more compliant when task demands came from a special educator consultant. In general, by the end

\section{References}

1 US Department of Education (2018) $40^{\text {th }}$ Annual Report to Congress on the Implementation of Individuals with Disabilities Education Act, 2018. Office of Special Education and Rehabilitative Services, p: 328.

2 US Department of Education (2008) 30 $30^{\text {th }}$ Annual Report to Congress on the Implementation of the Individuals with Disabilities Education Act, 2008. Office of Special Education and Rehabilitative Services, p: 248.

3 http://www.ada.gov/pubs/adastatute08mark.htm

4 National Council on Disability (2018) IDEA Series: Every Student Succeeds Act (ESSA) and students with disabilities. Washington, D.C.: National Council on Disability, p: 46.

5 Murawski WW, Scott KL, Council for Exceptional Children (2017) What really works with exceptional learners. Thousand Oaks, CA: Corwin, p: 392.

6 Shogren KA, Gross JMS, Forber-Pratt AJ, Francis GL, Satter AL, et al. (2015) The perspectives of students with and without disabilities on inclusive schools. Res Pract Pers Sev Disabil 40: 243-260.

7 Fraser D (2017) Teaching students with moderate to severe disabilities: You've got this! In: What Really Works with Exceptional of the school year, Tony's verbal and nonverbal communication had improved significantly [50-59].

\section{Conclusion}

In conclusion, outcomes of this case study show that inclusion of children with DS requires new thinking about the curriculum, better understanding of physical and socio-emotional needs of children with DS, implementation of evidence-based practices to address problem behaviors with high fidelity and increased collaborative efforts among general and special education teachers, other related services, and parents.

Furthermore, inclusion is being recognized worldwide as one of the greatest advances in special education. As stated in principles of the "Salamanca Statement", which supported education for all, "Each child has unique characteristics, interests, abilities and learning needs... Those with special educational needs must have access to regular schools which should accommodate them within a child-centered pedagogy capable of meeting these needs". Despite these efforts, the number of children with moderate to severe intellectual disabilities being educated in inclusive settings continues to remain small. Therefore, future research should consider investigating the efficacy of inclusive settings for children with moderate to severe intellectual disabilities. Specifically, teacher preparation in premises of inclusion education and their ability to accommodate and accept students with moderate and severe intellectual disability in their classrooms should be explored.
Learners (Murawski WW, Scott KL, Council for Exceptional Children Edn). Thousand Oaks, CA: Corwin, pp: 244-261.

8 Weiss S, Markowetz R, Kiel E (2018) How to teach students with moderate and severe intellectual disabilities in inclusive and special education settings: Teachers' perspectives on skills, knowledge and attitudes. Eur Educ Res J 17: 837-856.

9 Brownell MT, Sindelar PT, Kiely MT, Danielson LC (2010) Special education teacher quality and preparation: exposing foundations, constructing a new model. Except Child 76: 357-377.

10 Carpenter B, Egerton J, Cockbill B, Bloom T, Fotheringham J, et al. (2015) Engaging learners with complex learning difficulties and disabilities: a resource book for teachers and teaching assistants. New York: Routledge, p: 216.

11 Kurth JA, Lyon KJ, Shogren KA (2015) Supporting students with severe disabilities in inclusive schools: a descriptive account from schools implementing inclusive practices. Res Pract Pers Sev Disabil 40: $261-274$

12 Guralnick M, Bruder MB (2016) Early childhood inclusion in the United States: goals, current status, and future directions. Infants Young Child 29: 166-177.

13 https://www.ndss.org/about-down-syndrome/down-syndrome/ 
14 de Graaf G, van Hove G, Haveman M (2013) More academics in regular schools? The effect of regular versus special school placement on academic skills in Dutch primary school students with Down syndrome. J Intellect Disabil Res 57: 21-38.

15 Sirlopu D, Gonzalez R, Bohner G, Siebler F, Ordonez G, et al. (2008) Promoting positive attitudes toward people with down syndrome : the benefit of school inclusion programs. J Appl Soc Psychol 38: 2710-2736.

16 US Department of Health and Human Services, US Department of Education (2015) Policy statement on inclusion of children with disabilities in Early Childhood Programs: executive summary. Pp: 1-5.

17 Wan Y, Chiang C, Chen SC, Wang C, Wuang Y (2015) Profiles of visual perceptual functions in down syndrome. Res Dev Disabil 37: 112-118.

18 Wishart J (1993) Learning the hard way: avoidance strategies in young children with Down syndrome. Downs Syndr Res Pract 1: 47-55.

19 Robert JE, Price J, Malkin C (2007) Language and communication development in Down syndrome. Ment Retard Dev Disabil Res Rev 13: $26-35$.

20 Kazemi M, Salehi M, Kheirollahi M (2016) Down syndrome: current status, challenges and future perspectives. Int J Mol Cell Med 5: 125133.

21 Abbeduto L, Warren SF, Conners FA (2007) Language development in Down syndrome: from the prelinguistic period to the acquisition of literacy. Ment Retard Dev Disabil Res Rev 13: 247-261.

22 Ambreen A, Kumar A, Muthuswamy S, Jain S, Agarwal S (2015) Down syndrome: an insight of the disease. J Biomed Sci 22: 1-9.

23 Fidler DJ, Hepburn S, Rogers S (2006) Early learning and adaptive behavior in toddlers with Down syndrome: evidence for an emerging behavioral phenotype? Downs Syndr Res Pract 9: 37-44.

24 Laws $G$ (1998) The use of nonword repetition as a test of phonological memory in children with Down syndrome. J Child Psychol Psychiatry 39: $1119-1130$.

25 Alton S (1998) Differentiation not discrimination: delivering the curriculum for children with Down's syndrome in mainstream schools. Support Learn 13: 167-173.

26 Verucci L, Menghini D, Vicari S (2006) Reading skills and phonological awareness acquisition in Down syndrome. J Intellect Disabil Res 50: 477-491.

27 Coe DA, Matson JL, Russell DW, Slifer KJ, Capone GT, et al. (1999) Behavior problems of children with Down syndrome and life events. J Autism Dev Disord 29: 149-155.

28 Gilmore L, Campbell J, Cuskally M (2003) Developmental expectations, personality stereotypes, and attitudes towards inclusive education: community and teacher views of Down syndrome. Int J Disabil Dev Educ 50: 66-76.

29 Vaz S, Wilson N, Falkmer M, Sim A, Scott M, et al. (2015) Factors associated with primary school teachers' attitudes towards the inclusion of students with disabilities. PLoS One 10: e0137002.

30 Kemp C, Carter M (2005) Identifying skills for promoting successful inclusion in kindergarten. J Intellect Dev Disabil 30: 32-44.

31 Dooley P, Wilczenski FL, Torem C (2001) Using an activity schedule to smooth school transitions. J Posit Behav Interv 3: 57-61.

32 Quill KA (1995) Teaching children with autism: strategies to enhance communication and socialization. Albany, NY: Delmar.
33 Wishart J (2001) Motivation and learning styles in young children with Down syndrome. Downs Syndr Res Pract 7: 47-51.

34 Shogren KA, Faggella-Luby MN, Bae SJ, Wehmeyer ML (2004) The effect of choice-making as an intervention for problem behavior: a meta analysis. J Posit Behav Interv 6: 228-237.

35 Romaniuk C, Miltenberger RG (2001) The influence of preference and choice activity on problem behavior. J Posit Behav Interv 3: 152-159.

36 Peterson SMP, Caniglia C, Royster AJ (2001) Application of choicemaking intervention for a student with multiply maintained problem behavior. Focus Autism Other Dev Disabl 16: 240-246.

37 Kern L, Vorndran CM, Hilt A, Ringdahl JE, Adelman BE, et al. (1998) Choice as an intervention to improve behavior: a review of the literature. J Behav Educ 8: 151-169.

38 McAfee J (2002) Navigating the social world: A curriculum for individuals with Asperger syndrome, high functioning autism, and related disorders. Arlington, TX: Future Horizons Inc., p: 350.

39 Wolpert G (2001) What general educators have to say about successfully including students with Down syndrome in their classes. J Res Child Educ 16: 28-38.

40 Wang X, Bernas R, Eberhard P (2001) Effects of teachers' verbal and non-verbal scaffolding on everyday classroom performances of students with Down syndrome. Int J Early Years Educ 9: 72-80.

41 https://www.lwtears.com/hwt

42 Feeley K, Jones E (2008) Strategies to address challenging behavior in young children with Down syndrome. Downs Syndr Res Pract 12: 153-163.

43 Scattone D (2007) Social skills interventions for children with autism. Psychol Sch 44: 717-726.

44 Kabashi L, Kaczmarek LA (2017) Evaluating the efficacy of videoBased Instruction (VBI) on improving social initiation skills of children with autism Spectrum Disorder (ASD): a review of literature. Rev J Autism Dev Disord 4: 61-81.

45 Kabashi L, Epstein A (2017) Improving social initiations of children with autism using video self-modeling with video feedback: a case study. J Educ Soc Res 7: 111-121.

46 Baker J (2001) The social skills picture book: teaching play, emotion, and communication to children with autism. Arlington, TX: Future Horizons Inc., p: 197.

47 Porter J (2018) Entering Aladdin's cave: developing an app for children with Down syndrome. J Comput Assist Learn 34: 429-439.

48 Campbell J, Gilmore L, Cuskelly M (2003) Changing student teachers' attitudes towards disability and inclusion. J Intellect Dev Disabl 28: 369-379.

49 Vaughan M, Henderson A (2016) Exceptional educators: a collaborative training partnership for the inclusion of students with Down's syndrome. Support Learn 31: 46-58.

50 Rodriguez CC, Garro-Gil N (2015) Inclusion and integration on special education. Procedia Soc Behav Sci 191: 1323-1327.

51 Cunningham CC, Glenn S, Lorenz S, Cuckle P, Shepperdson B (1998) Trends and outcomes in educational placements for children with Down syndrome. Eur J Spec Needs Educ 13: 225-237.

52 Downing JE, Peckham-Hardin KD (2007) Inclusive education: What makes it a good education for students with moderate to severe disabilities? Res Pract Pers Sev Disabil 32: 16-30. 
53 Guralnick MJ (2002) Involvement with peers: comparisons between young children with and without Down's syndrome. J Intellect Disabil Res 46: 379-393.

54 Hamilton D (2005) An ecobehavioural analysis of interactive engagement of children with developmental disabilities with peers in inclusive preschools. Int J Disabil Dev Educ 52: 121-137.

55 Huang H, Diamond KE (2009) Early childhood teachers' ideas about including children with disabilities in programmes designed for typically developing children. Int J Disabil Dev Educ 56: 169-182.
56 Hunt P, Sot G, Maier J, Liboiron N, Bae S (2004) Collaborative teaming to support preschoolers with severe disabilities who are placed in general education early childhood programs. Topics Early Child Spec Educ 24: 123-142.

57 Lorenz S (1999) Making inclusion work for children with Down syndrome. Downs Syndr News Update 1: 175-180.

58 Odom SL (2000) Preschool inclusion: What we know and where we go from here. Topics Early Child Spec Educ 20: 20-27.

59 Silverman W (2007) Down syndrome: cognitive phenotype. Ment Retard Dev Disabil Res Rev 13: 228-236. 